Journal of Bangladesh Academy of Sciences, Vol. 36, No. 1, 71-78, 2012

\title{
FREQUENCY OF VIBRIO CHOLERAE IN THE WATER AND PLANKTON SAMPLES OF SOUTH-WESTERN COASTAL AQUATIC HABITATS OF BANGLADESH
}

\author{
MD. MANSURUL HAQUE*, MUNIRUL ALAM ${ }^{1}$ AND ABDUS SALAM \\ Department of Zoology, Jahangirnagar University, Savar, Dhaka-1342, Bangladesh
}

\begin{abstract}
Monthly environmental surveillance was carried out for three consecutive years in the coastal aquatic habitats of Mathbaria, with a view to assessing the culturability and abundance of $V$. cholerae. The study revealed that 93 samples (29\%) out of 324 were positive for V. cholerae $\mathrm{O} 1$ on TCBS and TTGA culture media but no sample was found positive for $V$. cholerae $\mathrm{O} 139$ in the same culture media. On the other hand, all the water and plankton samples were found positive for $V$. cholerae $\mathrm{O} 1$ and $\mathrm{O} 139$ in DFA counting technique. Similarly, V. cholerae non-O1 and nonO139 were detected from all samples through culture methods throughout the investigation period. $V$. cholerae $\mathrm{O} 139$ has been found to be absolutely non-responsive to artificial enrichment and culture media with the advancement of time. Therefore, water and plankton samples can also be concluded to be the additional reservoir of $V$. cholerae.
\end{abstract}

Key words: V. cholerae, Plankton, Coastal, Habitats, Reservoir, Epidemic

\section{INTRODUCTION}

Out of around 200 serogroups of Vibrio cholerae, only the $\mathrm{O} 1$ and $\mathrm{O} 139$ serogroups (VCO1 and O139) are the potential pathogen for causing sporadic and epidemic and cholera (Brayton et al. 1986). Until late 1970s and early 1980s, V. cholerae was believed to be highly host adapted and incapable of surviving longer than a few hours or days outside the human intestine. The endemic and seasonal cholera depends on the survival and the viable, but not necessarily culturable state of the bacterium in ecological niches in aquatic environments (Singleton et al. 1982). This microorganism is native to the microbial community of brackish and other aquatic environment (Miller et al. 1984). In Bangladesh, cholera epidemics occur twice every year, the highest peak during post monsoon (September - January) and second smaller peak during pre monsoon (March May). During inter-epidemic period $V$. cholerae cannot be cultured from the surface water, whereas in epidemic season it can be isolated from the patients' body as well as from surface water (Alam et al. 2006). When V. cholerae is not causing havoc in the human intestine, it may be found in diverse aquatic environments such as estuaries,

"Corresponding author: <mansurulju@yahoo.com>.

${ }^{1}$ Enteric and Food Microbiology Lab., Laboratory Sciences Division, ICDDR, B, Dhaka. 
rivers, ponds etc. (Islam et al. 1995, Lipp et al. 2003). V. cholerae can survive either as free living planktonic organisms in the water column or associated with phytoplankton and zooplankton (Islam 1990). Ecology, epidemiology, microbiology and remote sensing $V$. cholerae, a serious pathogen for humans, has been the subject of intense study for more than a century, yet the discovery that this bacterium is a natural inhabitant of riverine, estuarine and coastal waters throughout both temperate and tropical regions of the world was made only relatively recently (Colwell 1996). Some non-O1 serogroup strains produce toxin and have caused sporadic cases of cholera and small outbreaks of diarrhoeal disease without causing widespread epidemics (Albert et al. 1993). In response to environmental stress in aquatic environments, such as low concentrations of nutrients and low temperatures, $V$. cholerae $\mathrm{O} 1$ and non-O1 adopt a viable state that enables them to carry out metabolic functions and form colonies without being culturable (Huq et al. 1990, Colwell et al. 1985, Brayton et al. 1986, Colwell et al. 1992). The above information suggest that the ecology of Vibrio cholerae is mostly correlated with water and plankton samples of aquatic environment and the non culturable cells play a significant role in the seasonal epidemics of cholera (Alam et al. 2006).

It has been evident that $V$. cholerae is not vanished from nature with the recovery from sporadic or epidemic cholera, although the intestinal causative flora of the patients may be destroyed by the action of consumed antibiotics. Prolonged study reports regarding the ecology of $V$. cholerae is scarce. The current study was undertaken for a period of three consecutive years with a view to analysing the availability and culturability of pathogenic VCO1 and $\mathrm{O} 139$ and non-pathogenic VC non-O1 and nonO139 in water and in association with plankton in the aquatic environment immediately adjacent to the Bay of Bengal which will help to understand the possible link between proliferation of clinical and environmental cholera pathogen during epidemics and the possible role of environmental reservoir in the survival, persistence and transmission of cholera pathogen and to control it in an effective way keeping in mind the interest of planktons, humans and Vibrio cholerae.

\section{MATERIALS AND METHODS}

Several coastal ponds in different areas of Mathbaria under Pirojpur district were surveyed and after a series of vigilant supervision, three socially used ponds were selected. The chosen ponds were designated as: pond 1 (site-1), pond 2 (site-2) and pond 3 (site-3) and those ponds are learnt to be the potential reservoir of $V$. cholerae round the year. Sampling was carried out for a period of 36 months starting from October 2006 to September, 2009. A total of 324 samples comprising each of 108 water, phytoplankton and zooplankton samples were analysed for consecutive 36 months. In each round, a 5 liter sampling bottle was filled with water for 20 times from different areas of each pond 
and the same was filtered through 64 and $20 \mu \mathrm{m}$-pore-size nylon nets (Millipore Corp., Bedford, and Mass). The $64 \mu \mathrm{m}$ pore-sized net was placed sequentially in front of the 20 $\mu \mathrm{m}$ mesh-sized nylon net, with each having a collecting bucket at the base of the net. In this way, 100 liters of water was filtered from each pond in each round in order to get the final concentration of $50 \mathrm{ml}$ separately from two nets to analyse phyto- and zooplankton, respectively along with their possible attachment with $V$. cholerae. The nets were hung high manually to allow the plankton-free water to be filtered out from where $200 \mathrm{ml}$ water sample was collected into another bottle. So, there were three types of samples, viz. $50 \mathrm{ml}$ phytoplankton sample, $50 \mathrm{ml}$ zooplankton sample and $200 \mathrm{ml}$ plankton-free water sample in separately labelled vials from each pond and accordingly 9 types of samples ( 3 phytoplankton, 3 zooplankton and 3 water samples) were collected from three ponds in each turn. The same trend of sample collection was continued for consecutive 36 months so that the annual total number of samples were 108 and sum total of samples for three consecutive years were 324 (108 water samples, 108 zooplankton sample and 108 phytoplankton samples). All samples were collected by using aseptic technique in sterile dark Nalgene bottles (Nalgene Nunc International, St. Louis, Mo.) placed in an insulated plastic box and were transported at ambient air temperature from the site of collection to the central laboratory of the International Center for Diarrhoeal Disease Research, Bangladesh (ICDDR, B), in Dhaka. Both the samples from $64 \mu \mathrm{m}$ mesh-sized and $20 \mu \mathrm{m}$ mesh-sized plankton nets were further concentrated in the laboratory to a final volume of $5 \mathrm{ml}$ by filtering through a $0.22 \mu \mathrm{m}$ pore-size bacteriological membrane filter (Millipore). All the samples were processed in the following day, with approximately 20 hours of elapsing between sample collections in the field and processing in the laboratory. Samples were then enriched in alkaline peptone water (1\% peptone and $1 \%$ sodium chloride with $\mathrm{pH}$ adjusted to 8.5) referred as APW (Difco, Detroit, MI) and incubated at $37^{\circ} \mathrm{C}$ for 6 to 8 hours. Approximately, $5 \mu \mathrm{L}$ of enriched APW broth was streaked by using an inoculating loop on both thiosulfate-citrate-bile salts-sucrose (TCBS), and taurocholate-tellurite-gelatin agar (TTGA) and incubated at $37^{\circ} \mathrm{C}$ for 18 to 24 hours. TCBS and TTGA are two of the most commonly used and most widely studied selective plating media for cholera pathogen. Serological tests were performed using polyvalent and monoclonal antibodies specific for $V$. cholerae O1 and O139. Samples were preincubated overnight, in the dark, with $0.025 \%$ yeast extract (Difco) and $0.002 \%$ nalidixic acid (Sigma-Aldrich, St. Louis, MO). The samples were then centrifuged and the pellet was stained with cholera DFA reagents like fluorescein isothio cyanate-labelled antiserum specific for O1 or O139 (New Horizon Diagnostics, Columbia, MD). Fluorescent stained cells were observed and counted under UV light by using an epifluorescence microscope (Olympus, model Bx51) and were recorded with the help of a digital camera (Olympus DP20). 


\section{RESULTS AND DISCUSSION}

Overnight growth (18 to 24 hours) of $V$. cholerae on TCBS produced large (2 to 4 $\mathrm{mm}$ in diameter), slightly flattened, yellow colonies with opaque centers and translucent peripheries. The yellow color was due to the fermentation of sucrose in the medium. Non-sucrose-fermenting organisms produced large green to blue green colonies. Overnight growth of $V$. cholerae on TTGA appeared small, opaque colonies with slightly darkened centers. At 24 hours the centers of the colonies were darker and eventually the entire colony became grey because of the reduction of tellurite.

Out of 324 samples (108 phytoplankton, 108 zooplankton and 108 water) analysed between October, 2006 and September, 2009, 93 samples (29\%) were found V. cholerae O1 positive on TCBS and TTGA culture media where the water, phytoplankton and zooplankton samples were 32, 27 and 34, respectively. V. cholerae $\mathrm{O} 1$ positive samples in culture media were 26, 30 and 37 in first, second and third year, respectively. Contrary to this, the DFA detection method showed that all of the 324 samples (100\%) were positive for $V$. cholerae O1. Such findings suggest that $V$. cholerae $\mathrm{O} 1$ remains viable in water and in association with phyto- and zooplankton round the year irrespective of epidemic and inter-epidemic periods of cholera outbreaks, although they may not be found culturable in traditionally used culture media (Table 1).

Table 1. Frequency of $\mathrm{V}$. cholerae $\mathrm{O} 1$ from phytoplankton, zooplankton and water samples in culture and DFA.

\begin{tabular}{|c|c|c|c|c|c|c|c|c|c|c|}
\hline \multirow{3}{*}{ Site } & \multirow{3}{*}{$\begin{array}{c}\text { Sample } \\
\text { type }\end{array}$} & \multicolumn{3}{|c|}{ Oct'06 - Sept'07 } & \multicolumn{3}{|c|}{ Oct'07 - Sept'08 } & \multicolumn{3}{|c|}{ Oct'08 - Sept'09 } \\
\hline & & \multirow{2}{*}{$\begin{array}{c}\text { Total } \\
\text { sample }\end{array}$} & \multicolumn{2}{|c|}{ VCO1 } & \multirow{2}{*}{$\begin{array}{c}\text { Total } \\
\text { sample }\end{array}$} & \multicolumn{2}{|c|}{$\mathrm{VCO} 1$} & \multirow{2}{*}{$\begin{array}{c}\text { Total } \\
\text { sample }\end{array}$} & \multicolumn{2}{|c|}{ VCO1 } \\
\hline & & & Culture & DFA & & Culture & DFA & & Culture & DFA \\
\hline \multirow{4}{*}{1} & $\mathrm{~W}$ & 12 & 4 & 12 & 12 & 5 & 12 & 12 & 5 & 12 \\
\hline & $\mathrm{Z}$ & 12 & 2 & 12 & 12 & 3 & 12 & 12 & 4 & 12 \\
\hline & $\mathrm{P}$ & 12 & 3 & 12 & 12 & 4 & 12 & 12 & 4 & 12 \\
\hline & $\mathrm{W}$ & 12 & 2 & 12 & 12 & 3 & 12 & 12 & 5 & 12 \\
\hline \multirow[t]{3}{*}{2} & $\mathrm{Z}$ & 12 & 2 & 12 & 12 & 3 & 12 & 12 & 4 & 12 \\
\hline & $\mathrm{P}$ & 12 & 4 & 12 & 12 & 4 & 12 & 12 & 4 & 12 \\
\hline & $\mathrm{W}$ & 12 & 3 & 12 & 12 & 2 & 12 & 12 & 3 & 12 \\
\hline \multirow[t]{2}{*}{3} & $\mathrm{Z}$ & 12 & 2 & 12 & 12 & 3 & 12 & 12 & 4 & 12 \\
\hline & $\mathrm{P}$ & 12 & 4 & 12 & 12 & 3 & 12 & 12 & 4 & 12 \\
\hline \multicolumn{2}{|r|}{ Total } & 108 & 26 & 108 & 108 & 30 & 108 & 108 & 37 & 108 \\
\hline
\end{tabular}

(W = Water, $\mathrm{P}=$ Phytoplankton, $\mathrm{Z}=$ Zooplankton)

In the three years study, none of the 324 samples showed V. cholerae 0139 on standard culture media like TCBS and TTGA but all the samples were found positive for it in DFA. Such findings also support the concept of VCO139 being viable but nonculturable (VBNC) bacteria and they also remain present in the aquatic environment 
throughout the year, either free-living or in association with planktons (Table 2). The non-recovery of VCO1 and $\mathrm{O} 139$ by standard culture methods during inter-epidemic period is mysterious and might be a mechanism of their persistence to be studied more and the factors that trigger their seasonal as well as annual bloom need to be investigated thoroughly.

Table 2. Frequency of $V$. cholerae 0139 from phytoplankton, zooplankton and water samples in culture and DFA.

\begin{tabular}{|c|c|c|c|c|c|c|c|c|c|c|}
\hline \multirow{3}{*}{ Site } & \multirow{3}{*}{$\begin{array}{c}\text { Sample } \\
\text { type }\end{array}$} & \multicolumn{3}{|c|}{ Oct'06 - Sept'07 } & \multicolumn{3}{|c|}{ Oct'07 - Sept'08 } & \multicolumn{3}{|c|}{ Oct'08 - Sept'09 } \\
\hline & & \multirow{2}{*}{$\begin{array}{c}\text { Total } \\
\text { sample }\end{array}$} & \multicolumn{2}{|c|}{ VC O139 } & \multirow{2}{*}{$\begin{array}{c}\text { Total } \\
\text { sample }\end{array}$} & \multicolumn{2}{|c|}{ VC O139 } & \multirow{2}{*}{$\begin{array}{c}\text { Total } \\
\text { sample }\end{array}$} & \multicolumn{2}{|c|}{ VC O139 } \\
\hline & & & Culture & DFA & & Culture & DFA & & Culture & DFA \\
\hline \multirow{3}{*}{1} & W & 12 & 0 & 12 & 12 & 0 & 12 & 12 & 0 & 12 \\
\hline & $\mathrm{Z}$ & 12 & 0 & 12 & 12 & 0 & 12 & 12 & 0 & 12 \\
\hline & $\mathrm{P}$ & 12 & 0 & 12 & 12 & 0 & 12 & 12 & 0 & 12 \\
\hline \multirow{3}{*}{2} & W & 12 & 0 & 12 & 12 & 0 & 12 & 12 & 0 & 12 \\
\hline & $\mathrm{Z}$ & 12 & 0 & 12 & 12 & 0 & 12 & 12 & 0 & 12 \\
\hline & $\mathrm{P}$ & 12 & 0 & 12 & 12 & 0 & 12 & 12 & 0 & 12 \\
\hline \multirow{3}{*}{3} & W & 12 & 0 & 12 & 12 & 0 & 12 & 12 & 0 & 12 \\
\hline & Z & 12 & 0 & 12 & 12 & 0 & 12 & 12 & 0 & 12 \\
\hline & $P$ & 12 & 0 & 12 & 12 & 0 & 12 & 12 & 0 & 12 \\
\hline & Total & 108 & 0 & 108 & 108 & 0 & 108 & 108 & 0 & 108 \\
\hline
\end{tabular}

(W = Water, $\mathrm{P}=$ Phytoplankton, $\mathrm{Z}=$ Zooplankton)

It has been revealed from the present study that $V$. cholerae non-O1 and non-O139 were present on TCBS in all of water, phytoplankton and zooplankton samples throughout the study period. These findings suggest that $V$. cholerae non-O1 and non$\mathrm{O} 139$ are the aboriginal inhabitants of water and other aquatic micro-flora and fauna especially phyto- and zooplankton (Table 3 ).

Islam et al. (1993) used culture method and isolated VCO1 strains from 1\% and O39 from $12 \%$ of 92 water samples from ponds, lakes, rivers and canals in rural Matlab and urban Dhaka. But in the present study with the same culture technique, VCO1 was collected from $29 \%$ of 324 water and plankton samples where the total water samples were 108 of which 32 were positive for VCO1 but no sample irrespective of plankton and water was found positive for VCO139. Complete absence of VCO139 on standard culture media from 324 samples is intriguing which suggests that VC O139 flora are becoming more and more non-culturable with the elapse of time and unabated environmental pollution with drastic effect upon aquatic habitats. Felsenfeld (1974) has mentioned some authors claim that $V$. cholerae may survive in water, particularly seawater for up to two months. Contrary to this, the present findings have corroborated that both pathogenic and non-pathogenic $V$. cholerae can survive in semi-saline aquatic habitats irrespective of seasons round the year either in active and culturable or dormant and non-culturable state. 
Table 3. Frequency of $V$. cholerae non-O1 and non-O139 from water and plankton samples in culture.

\begin{tabular}{|c|c|c|c|c|c|c|c|}
\hline \multirow{3}{*}{ Site } & \multirow{3}{*}{$\begin{array}{l}\text { Sample } \\
\text { type }\end{array}$} & \multicolumn{2}{|c|}{ Oct'06 - Sept'07 } & \multicolumn{2}{|c|}{ Oct'07 - Sept'08 } & \multicolumn{2}{|c|}{ Oct'08 - Sept'09 } \\
\hline & & \multirow{2}{*}{$\begin{array}{c}\text { Total } \\
\text { sample }\end{array}$} & $\begin{array}{c}\text { VC non-O1 and } \\
\text { non-O139 }\end{array}$ & \multirow{2}{*}{$\begin{array}{c}\text { Total } \\
\text { sample }\end{array}$} & $\begin{array}{c}\mathrm{VC} \text { non-O1 } \\
\text { and non-O139 }\end{array}$ & \multirow{2}{*}{$\begin{array}{c}\text { Total } \\
\text { sample }\end{array}$} & $\begin{array}{c}\mathrm{VC} \text { non-O1 } \\
\text { and non-O139 }\end{array}$ \\
\hline & & & Culture & & Culture & & Culture \\
\hline \multirow{4}{*}{1} & $\mathrm{~W}$ & 12 & 12 & 12 & 12 & 12 & 12 \\
\hline & $\mathrm{Z}$ & 12 & 12 & 12 & 12 & 12 & 12 \\
\hline & $\mathrm{P}$ & 12 & 12 & 12 & 12 & 12 & 12 \\
\hline & $\mathrm{W}$ & 12 & 12 & 12 & 12 & 12 & 12 \\
\hline \multirow[t]{3}{*}{2} & $\mathrm{Z}$ & 12 & 12 & 12 & 12 & 12 & 12 \\
\hline & $\mathrm{P}$ & 12 & 12 & 12 & 12 & 12 & 12 \\
\hline & $\mathrm{W}$ & 12 & 12 & 12 & 12 & 12 & 12 \\
\hline \multirow[t]{3}{*}{3} & $\mathrm{Z}$ & 12 & 12 & 12 & 12 & 12 & 12 \\
\hline & $\mathrm{P}$ & 12 & 12 & 12 & 12 & 12 & 12 \\
\hline & Total & 108 & 108 & 108 & 108 & 108 & 108 \\
\hline
\end{tabular}

(W = Water, $\mathrm{P}=$ Phytoplankton, $\mathrm{Z}=$ Zooplankton)

Colwell et al. (1985) demonstrated that the capacity of $V$. cholerae to undergo the starvation response as well as to enter the viable but non-culturable state makes it clear that long-term survival of this organism in the environment, perhaps for years must be considered a source of the organism in cholera epidemics. When the cells are subjected to nutrient depletion or addition or to reduction or elevation in salinity and temperature, the cells rapidly go non-culturable but remain viable and potentially pathogenic. The present findings were based on diverse environmental samples from several sites which are plausibly compatible with the findings as quoted. The results of the present study also showed concordance with the findings of Huq et al. (1990) who investigated that $V$. cholerae cells do not necessarily die when discharged into aquatic environment but instead remain viable and are capable of transforming into a culturable state if the environmental conditions again become viable.

Brayton et al. (1986) demonstrated by both field and laboratory studies that $V$. cholerae indeed undergoes conversion to a viable but non-culturable state whereby the cells are reduced in size and become ovoid but, in contrast the starved cells do not grow at all on standard laboratory media yet remain responsive to nalidixic acid and continue to assimilate radio-labeled substrate. They also detected that the percentage of culturable $V$.cholerae $\mathrm{O} 1$ cells ranged from 13 (at $10^{\circ} \mathrm{C}$ and $2.5 \%$ salinity) to $87 \%$ (at $25^{\circ} \mathrm{C}$ and $0.5 \%$ ) of AODC. These findings substantiate the present findings to some extent although radio-labeled substrates were not testified in the present study.

Garg et al. (2003) found 267 isolates (68\%) belonging to VC non-O1 and non-O139 serogroups out of 391 environmental isolates. Whereas in the current study, all 324 
environmental samples comprising plankton and water samples showed presence of $\mathrm{VC}$ non-O1 and non-O139. It seems that presently the environmental isolates are more contaminated with non VC non-O1 and non- O139 than that of 2003.

\section{ACKNOWLEDGEMENT}

Authors thankfully acknowledge the logistic support of ICDDR,B authority to carry out the research.

\section{REFERENCES}

Alam, M., M. Sultana, G. B. Nair, R. B. Sack, D. A. Sack, A. K. Siddique, A. Ali, A. Huq and R. R. Colwell. 2006. Toxigenic Vibrio cholerae in the aquatic environment of Mathbaria, Bangladesh. Appl. Environ. Microbiol. 72: 2849-2855.

Albert, M. J., A. K. Siddique, M.S. Islam, A.S.G. Faruque, M. Ansaruzzaman, S.M. Faruque and R.B. Sack. 1993. Large outbreak of clinical cholera due to Vibrio cholerae non-O1 in Bangladesh. Lancer 341: 704.

Brayton, P. R., D. B. Roszack, L. M. Palmer, A. Huq, D. J. Grimes and R. R. Colwell. 1986. Fluorescent antibody enumeration of $V$. cholerae in the marine environment. IFREMER. 3: 507-514.

Colwell, R. R. 1996. Global climate and infectious disease: the cholera paradigm. Science. 274: 2025- 2031.

Colwell, R. R., J. A. K. Hasan, A. Huq, L. Loomis, R. J. Siebling, M. Torres, A. Galvez, S. Islam and D. Bernstein. 1992. Development and evaluation of a rapid, simple sensitive monoclonal antibody-based co-agglutination test for direct detection of V. cholerae O1. FEMS Microbiol. Lett. 97: 215-220.

Colwell, R. R., P. R. Brayton, D. J. Grimes, D. R. Rozsak, S. A. Huq and L. M. Palmer. 1985. Viable, but non-culturable Vibrio cholerae and related pathogens in the environment: implication for release of genetically engineered microorganisms. Bio-Technology 3: 817-820.

Felsenfeld, O. 1974. The survival of cholera vibrios. p 359 -366. In: D. Barua and W. Burrows (ed.), Cholera, W.B. Saunders, Philadelphia.

Ganesh, E. A., S. D. K. Chandrasekar, G. Arun and S. Balamurugan. 2010. Monitoring of total heterotrophic bacteria and Vibrio sp. in an aquaculture p ond. Journal of Biological Sciences 2(1): 48-52.

Garg, P., A. Aydanian, D. J. Smith, M. Jr. Glenn, G. B. Nair and O.C. Stine. 2003. Moleculer epidemiology of O139 Vibrio cholerae; mutation, lateral gene transfer and founder flush. Emerg. Infect Dis. 9: 810-814.

Hood, M. A. and G.E. Ness. 1982. Survival of Vivrio cholerae and Escherichia coli in estuarine waters and sediments. Appl. Environ. Microbiol. 9: 65-75.

Huq, A., R. R. Colwell, R. Rahman, A. Ahmed, M. A. R. Chowdhury, S. Parveen, D. A. Sack and R. Russek-Cohen. 1990. Detection of Vibrio cholerae O1 in the aquatic environment by fluorescentmonoclonal antibody and culture methods. Appl. Environ. Microbiol. 56: 2370-2373.

Islam, M. S. 1990. Effect of various biophysicochemical conditions on toxigenicity of Vibrio cholerae $\mathrm{O} 1$ during survival with a green alga, Rhizoclonium fontanum, in an artificial aquatic environment. Canadian Journal of Microbiology 36: 464-468.

Islam, M. S., B. S. Draser, and R.B. Sack. 1995. The aquatic environment as reservoir of Vibrio cholerae: a review. J. Diarrhoeal Dis. Res. 11: 197-206. 
Islam, M.S., M.K. Hasan, M.A. Miah, F. Qadri, M.Yunus, R.B. Sack and M.J. Albert. 1993. Isolation of Vibrio cholerae O139 Bengal from water in Bangladesh. Lancer 342: 430.

Lipp, E. K., A. Huq and R. R. Colwell. 2003. Effects of global climate on infectious disease: the cholera model. Clin. Microbiol. Rev. 15: 757-770.

Miller, C. J., B. S. Drasar and R. G. Feachem. 1984. Response of toxigenic Vibrio cholerae O1 to physico-chemical stresses in aquatic environments. Journal of Hygiene 93: 475-495.

Singleton, E. L., R. W. Atwell, M. S. Jsngi and R. R.Colwell. 1982. Influence of salinity and nutrient concentration on survival and Growth of Vibrio cholerae in aquatic microcosm. Appl. Environ. Microbiol. 43: 1080-1085.

(Received revised manuscript on 6 March, 2012) 